\title{
O programa pós-graduação em ensino na Educação Básica do CEPAE/UFG: um olhar sobre sua história, experiências e possibilidades.
}

\author{
The Postgraduate Program in Teaching Basic Education at CEPAE-UFG: a look at its \\ history, experiences and possibilities
}

\author{
Glauco Roberto Gonçalves ${ }^{1}$ \\ Marilza Vanessa Rosa Suanno ${ }^{2}$ \\ Vivianne Fleury de Faria ${ }^{3}$
}

\section{Resumo}

O objetivo deste artigo é relatar a história de formação e desenvolvimento do Programa de Pós Graduação em Ensino na Educação Básica do Centro de Ensino e Pesquisa Aplicada à Educação da Universidade Federal de Goiás (PPGEEB/CEPAE/UFG), um programa de mestrado profissionalizante multidisciplinar eminentemente voltado para docentes da rede pública (municipal, estadual e federal), bem como de profissionais da rede privada e de educadores que atuem em espaços informais e não formais de ensino, possibilitando que tais docentes realizem pesquisas e estudos sobre suas práticas educacionais e sobre as políticas educacionais e de ensino. Para isto, recorremos a um breve histórico deste Centro de Ensino para contextualizar e apresentar as especificidades deste programa com destaque para a formação de professores, pesquisa com intervenção e criação de produtos educacionais e a relação entre projetos de ensino transdisciplinares do CEPAE e pesquisa escolares desenvolvidas e em andamento no PPGEEB. Finalmente, relatamos duas pesquisas, uma em fase de finalização e outra já concluída, a fim de demonstrar o tipo de produção oriunda do nosso mestrado profissional.

Palavras-chave: Ensino; Mestrado Profissional; Transdisciplinaridade; Educação Pública.

\footnotetext{
${ }^{1}$ Doutor em Geografia Humana pela Universidade de São Paulo, professor efetivo do Centro de Ensino e Pesquisas Aplicada à Educação da Universidade Federal de Goiás. Lattes: http://lattes.cnpq.br/3347218484822776. Orcid iD https://orcid.org/0000-0002-1920-157X. Goiânia, Goiás, Brasil. E-mail: glauco.goncalves@ufg.br

${ }^{2}$ Doutora em Educação pela Universidade Católica de Brasília - UCB (2015). Doutorado sanduíche realizado na Universidade de Barcelona - UB (2011/2012). Lattes: http://lattes.cnpq.br/7736117519324293. Orcid iD https://orcid.org/0000-0001-5892-1484. Goiânia, Goiás, Brasil. E-mail: marilzasuanno@uol.com.br

3 Doutora em Literatura Brasileira pela UNB, Lattes: https://wwws.cnpq.br/cvlattesweb/PKG MENU.menu?f cod=0FA9512BA2A8B91656C2B469A0C0 8354 https://orcid.org/0000-0003-4624-4484 Goiânia, Goiás, Brasil. E-mail: vivianne fleury faria@ufg.br
} 


\begin{abstract}
The purpose of this article is to report the history of formation and development of the Graduate Program in Education in Basic Education at the Center for Teaching and Research Applied to Education at the Federal University of Goiás (PPGEEB / CEPAE / UFG), a multidisciplinary professionalizing master's program eminently geared towards public school teachers (municipal, state and federal), as well as professionals from the private network and educators who work in informal and non-formal teaching spaces, enabling such teachers to carry out research and studies on their educational practices and on educational and teaching policies. For this, we use a brief history of this Teaching Center to contextualize and present the specificities of this program with emphasis on teacher training, research with intervention and creation of educational products and the relationship between CEPAE transdisciplinary teaching projects and school research developed and in progress at PPGEEB. Finally, we report two researches, one being finalized and the other already completed in order to demonstrate the type of production coming from our professional master's degree.
\end{abstract}

Keywords: Teaching; Professional Master's; Transdisciplinarity; Public education.

\title{
Introdução
}

Este artigo tem por objetivo apresentar o Mestrado Profissional em Ensino na Educação Básica do Programa de Pós-Graduação Stricto Sensu do Centro de Ensino e Pesquisa Aplicado à Educação da Universidade Federal de Goiás (PPGEEB/CEPAE/UFG).

Nosso texto se divide em três momentos. No primeiro, recorremos a um breve histórico de constituição do Centro de Ensino e Pesquisa Aplicado à Educação da Universidade Federal de Goiás - CEPAE/UFG - como parte pressuposta e imante da formação do programa de pós-graduação que iremos abordar. Entender a formação do CEPAE/ UFG coloca-se como um movimento imprescindível para compreensão do Mestrado Profissional em Ensino na Educação Básica do Programa de Pós-Graduação Stricto Sensu PPGEEB/CEPAE /UFG. Nesta primeira parte, apresentamos um projeto de caráter transdisciplinar desenvolvido por nós professores com estudantes do Ensino Médio do CEPAE-UFG e bolsistas PIBIDs. Ao abordar este nosso projeto o intuito é evidenciar a 
presença de práticas pedagógicas que avançam para além das convenções e da grade que compõe o currículo, expondo, assim, com este exemplo específico, a importância de centros de ensino e de escolas de aplicação em que atuam professores pesquisadores em favor de transformações pedagógicas nos processos de ensino e aprendizagem da educação básica.

No segundo momento, lançamos nosso olhar sobre o programa de pós-graduação em questão, o PPGEEB/CEPAE/UFG, trazendo dados e informações constitutivas de sua história, evidenciando algumas de suas características centrais, salientando seu caráter multidisciplinar e sua importante contribuição na formação continuada de professores da Educação Básica de Goiânia e de Goiás, fundamentalmente de docentes que atuam na rede pública estadual, municipal e federal.

O terceiro momento deste artigo é destinado a algumas das experiências de pesquisas e de ensino vivenciadas por nós, autores deste texto, dentro do PPGEEB/CEPAE/UFG. Nesta parte do texto adotamos um movimento que vai do geral ao particular, que começa com a abordagem das concepções metodológicas desenvolvidas pelo Departamento de Língua Portuguesa, exemplificada com uma pesquisa de mestrado em fase de finalização para, em seguida, abordar uma outra experiência singular, esta já concluída, desenvolvida por um mestrando do programa na área de Geografia. Nesta terceira parte do texto, longe de almejarmos algo que aponta para a totalidade dos processos constitutivos do programa, buscamos elencar algumas características e vivências que ilustrassem processos metodológicos e sua efetividade postos em destaque nestes exemplos de pesquisas específicas.

Trata-se, portanto, de um artigo que busca apresentar um olhar panorâmico sobre o Centro de Ensino e Pesquisa Aplicado a Educação e seu programa de pós-graduação, situados dentro da Universidade Federal de Goiás, apontando para suas especificidades regionais e locais em dialogo com condições estruturais e históricas de ordem geral, bem como para os muitos desafios postos em curso na educação pública e de sua formação docente.

\section{Metodologia}


O presente artigo apresenta resultados de pesquisa documental sobre a história e o processo de criação do Programa de Pós Graduação em Educação em Ensino Básico do Centro de Ensino e Pesquisa Aplicada à Educação da Universidade Federal de Goiás (PPGEEB/CEPAE/UFG) e sua articulação com a história e a identidade desta escola de Educação Básica. Neste breve histórico para situar a articulação entre ensino, pesquisa, extensão e mestrado profissional foram apresentados apontamentos sobre a vinculação com a Rede Internacional de Escolas Criativas (RIEC), com o projeto de pesquisa Formação do leitor literário na Educação Básica e com o projeto de ensino intitulado Projeto Transdisciplinar O que é ser brasileiro? (CEPAE/UFG).

\section{Histórico do CEPAE}

O CEPAE foi fundado, ainda na condição de Colégio de Aplicação, por meio do Decreto-lei no 9.053, de 12 de março de 1966. Ele surge vinculado e assentado no prédio da Faculdade de Educação desta universidade. Suas atividades tiveram início em março de 1968, no bojo da Reforma Universitária daquele mesmo ano com o objetivo de ser:

[...] um laboratório experimental de técnicas e processos didáticos visando ao aprimoramento da metodologia de ensino; constituir-se em escola experimental para novos cursos previstos na legislação vigente, bem como para cursos com currículos, métodos e períodos escolares próprios, ajustando-se estes, para fins de validade, às exigências legais; servir como campo de estágio supervisionado para a licenciatura e para as habilitações do curso de pedagogia. (SILVA, 2018, p. 20-21)

Até 1980, o Colégio de Aplicação da FE/UFG era formado por professores e professoras da carreira do $1^{\circ}$ e $2^{\circ}$ graus e por docentes da Faculdade de Educação, que também atuavam ministrando aulas na Educação Básica. Contudo, o Colégio passou por profundas alterações vinculadas às reivindicações da greve realizada ainda no ano de 1980, quando seus docentes passaram a figurar na carreira do magistério superior, passando á condição de professores de $3^{\circ}$ grau. Nota-se que esta condição, advinda de reivindicação e 
luta política, gerou condições e especificidades para o CEPAE, visto que grande parte dos Colégios de Aplicação das universidades públicas no Brasil (tanto estaduais como federais) tem seus e suas docentes vinculados à carreira da Educação Básica. A configuração docente como parte da carreira de ensino superior traz ao CEPAE liames com atividades de ensino, pesquisa e extensão, o promovendo não só como centro de ensino, mas também como lócus de realização e de promoção de pesquisas.

Dois anos depois, em 1982, criou-se o Departamento de Estudos Aplicados à Educação da Faculdade de Educação/UFG, formado por profissionais que atuavam no Colégio de Aplicação. Esta estrutura e forma de funcionamento perdurou até março de 1994, quando foi formalmente criado o Centro de Ensino e Pesquisa Aplicada à Educação, por meio da Portaria ${ }^{\circ}$ 0063, de autoria do reitor Ary Monteiro do Espírito Santo, da Universidade Federal de Goiás (SILVA, p.21:2018).

Além de um corpo docente de magistério superior, outro caráter que distingue o CEPAE é a sua forma de acesso de novos alunos. Até o início de 1976, o ingresso no então Colégio de Aplicação da UFG se dava por meio de exames de admissão. Em 1977, o sistema de entrada adotado passa a ser de $50 \%$ das vagas destinadas por meio de sorteios públicos destinadas à comunidade e as outras 50\% reservadas aos servidores da UFG. Tal condição perdurou até 1988, quando a totalidade das vagas ofertadas passou a ser feita por meio de sorteios públicos, eliminando assim a reserva da metade das vagas aos servidores, que passaram a disputá-las de modo isonômico juntamente com a comunidade. Tal alteração na composição das vagas disponíveis no então Departamento de Estudos Aplicados à Educação da Faculdade de Educação da UFG representou um avanço, fruto do aprimoramento do sentido público desta escola, que já figurava como um centro de ensino de Educação Básica de destaque pela sua qualidade, seu caráter laico e gratuito.

Até a presente data, a forma de ingresso de estudantes no CEPAE continua se dar por meio de sorteios. Em 2018, o CEPAE contava com 767 vagas destinadas a todos os níveis da Educação Básica, indo da Educação Infantil ao último ano do Ensino Médio - algo que não sofreu alteração significativa até aqui (SILVA, p.21:2018) ${ }^{4}$. Em nosso entendimento, o sorteio de vagas, sem reservas a docentes ou servidores, configura-se como o modo mais democrático em um cenário onde não há vagas disponíveis para todos que desejam estudar nesta escola.

\footnotetext{
${ }^{4}$ Os dados e caracterizações sobre os estudantes de nível de pós-graduação deixaremos para mais adiante, constituindo um dos elementos centrais deste trabalho.
} 
Com efeito, convém salientar que o número de inscritos para concorrer a uma vaga no CEPAE é enorme em todos os anos, tal procura estando certamente associada à qualidade da educação - pública, laica e gratuita - ofertada pela escola, que via de regra alcança colocação entre as melhores, quando não a melhor, escola pública de Educação Básica da cidade de Goiânia e do Estado de Goiás ${ }^{5}$. É relevante destacar que o processo seletivo por meio de sorteio de vagas não promove nenhuma clivagem de desempenho dos e das estudantes sorteados, o que gera uma condição bastante heterogênea no perfil socioeconômico dos e das discentes, bem como em seus níveis de aprendizagem e de desempenho escolar ${ }^{6}$.

Vale salientar que o CEPAE/ UFG é membro do Conselho Nacional dos Dirigentes das Escolas de Educação Básica (CONDICAP), que reúne 17 unidades de Educação Básica vinculadas à Instituições Federais de Ensino Superior (IFES) do Brasil. A participação no CONDICAP traz às práticas político-pedagógicas do CEPAE/UFG uma dimensão e diálogo de conjunto, e o insere em um campo de atuação de caráter nacional.

É importante evidenciar, ainda, que o CEPAE/ UFG desde sua origem não atende apenas à Educação Básica, é também um vigoroso campo multidisciplinar de estágios supervisionados, atribuição que estava entre as razões de sua fundação. Mas deixou de ser nomeado como Colégio de Aplicação, pois sua dimensão de atuação tornou-se mais ampla, sendo - como o próprio nome diz - uma unidade específica da UFG em que se desenvolvem pesquisas notadamente voltadas ao ensino e à formação de professores e assentada no tripé

\footnotetext{
${ }^{5}$ Em 2017, a matéria da Folha de São Paulo apontava que: "Liderando a lista, aparece o Centro de Ensino e Pesquisa Aplicada à Educação (CEPAE) da Universidade Federal de Goiás. A escola conseguiu uma média de 551.33 nas provas objetivas e 667.14 na redação". In: https://www.folhaz.com.br/noticias/melhores-colegios-publicos-de-goiania Em 2016, o CEPAE foi classificado como a melhor escola pública de Goiás, tendo notas médias no Enem maiores que a média das notas obtidas pelas escolas particulares do Brasil: "O Centro de Ensino e Pesquisa Aplicada à Educação (CEPAE) é a melhor escola pública do Estado de Goiás*. Esta afirmação é do Instituto Nacional de Estudos e Pesquisas (Inep), órgão ligado ao Ministério da Educação, que divulgou ontem, 4/10, o ranking do desempenho das escolas brasileiras no Exame Nacional do Ensino Médio (Enem) 2015. Com a nota média de 559 dos seus estudantes, o CEPAE superou a média das escolas particulares brasileiras, de 556.”. In: https://www.ufg.br/n/91950-cepae-ufg-e-a-melhor-escolapublica-de-goias

${ }^{6} \mathrm{O}$ que difere radicalmente do modo de operar dos colégios estaduais militarizados-policializados em Goiás, por exemplo, que cobram taxas mensais dos e das estudantes, fato que cria um crivo sócioeconômico que reflete fortemente no desempenho destas escolas (declaram que tais taxas não são obrigatórias, mas na prática, comprovadamente, em depoimentos, pesquisas e textos jornalísticos, fica patente a obrigatoriedade deste pagamento mensal). Não são raros os processos seletivos para admissão nestes colégios militarizados-policializados, e mesmo a transferência compulsória de estudantes com baixos desempenho é prática recorrente, visando a obtenção de notas altas no IDEB para propagar a eficácia do ensino de polícia.
} 
Ensino, Pesquisa e Extensão que caracteriza qualitativamente o sentido da universidade pública brasileira ${ }^{7}$.

Como instâncias consultivas e atuantes do CEPAE/ UFG, convém destacar o Grêmio Estudantil Damiana da Cunha e a Associação de Pais e Mestres. O Grêmio é uma instituição independente, atua de modo autogerido e com participação autônoma dos estudantes. Tendo voz garantida em reuniões deliberativas, foi protagonista no processo das ocupações ocorridas durante o ano de 2016 contra a PEC 95, quando promoveu a primeira ocupação da longa lista de unidades que posteriormente foram aderindo ao movimento na Universidade Federal de Goiás $^{8}$. A Associação de Pais e Mestres atua junto à comunidade cepaeana, com voz e voto nos Conselhos Diretores do CEPAE/ UFG, tomando parte das decisões e deliberações administrativas e pedagógicas da escola, uma vez que se entende que sem a participação ativa da família não é possível uma escola democrática.

É digno de nota, ainda - mas não menos importante - que desde 2012 o CEPAE/ UFG integra a Rede Internacional de Escolas Criativas (RIEC), criada por pesquisadoras e pesquisadores espanhóis e latino-americanos, dentre outros, liderados pelo professor emérito Dr. Saturnino de La Torre, da Universidade de Barcelona, Espanha. A Ata de criação da RIEC foi assinada no IV Fórum Internacional sobre Inovação e criatividade: adversidade e escolas criativas - INCREA/2012, realizado na Universidade de Barcelona, nos dias 27 e 28 de junho de 2012. Esta inclusão do CEPAE/ UFG junto a RIEC se deu por meio da professora Dra. Marilza Vanessa Rosa Suanno, da Faculdade de Educação UFG, que percebeu a vocação criativa, problematizadora, plural e transdisciplinar desta escola em que, atualmente, no ano

\footnotetext{
${ }^{7}$ A Resolução do Consuni n 32/2014 estabelece, normatiza e atualiza tais atribuições.

${ }^{8}$ É fascinante notar que dentre o conjunto de estudantes de graduação e de pós-graduação da UFG foram os estudantes da Educação Básica que tomaram a frente nos processos de ocupação contra a PEC 95, durante o ano de 2016. Para maiores desdobramentos deste processo: GONÇALVES, Glauco R. "Pedagogia da ocupação (e ocupação da pedagogia): as escolas ocupadas e suas práticas de educação democrática no Ensino Básico." In: MESQUITA, Deise, N,C.(org.) Escola de educação básica para todos. Goiânia: Editora Espaço Acadêmico, 2017.

Outra referência fundamental para compreender a história e o sentido da atuação do Grêmio Damiana da Cunha é o capítulo de livro, escrito por duas estudantes do CEPAE e deste grêmio ainda quando eram estudantes de Ensino Médio. O texto intitulado "Grêmio Damiana da Cunha: uma análise teórica e empírica das transformações no CEPAE." de autoria de Isadora Malveira Oliveira e Stefany Monteiro Peixoto está no livro MESQUITA, Deise N. de C (org). Centro de Ensino e Pesquisa Aplicada à Educação da Universidade Federal de Goiás: 50 anos de história. Goiânia, Gráfica da UFG, 2018.
} 
de 2020, tem cadastrados e em andamento 18 projetos de pesquisa, 41 projetos de extensão e 12 projetos de ensino.

Com efeito, o corpo docente do CEPAE/ UFG, ciente do privilégio e da responsabilidade de trabalhar em um centro de excelência educacional, compreende o desafio e a necessidade que é constituir uma escola que atente para as transformações do mundo e da sociedade, afinada com o século XXI e com a proposta de religamento dos saberes. De acordo com Suanno (2015, p. 117):

A transdisciplinaridade busca a abertura das disciplinas àquilo que as atravessa e as ultrapassa, não propõe que se abandone as disciplinas, ou que se abandone os processos de ensino. Propõe-se que os contextos educativos, com rigor, abertura e tolerância/respeito, busquem religar, globalizar, enfim, transdisciplinarizar conhecimentos, saberes e emoções. Possibilitando a construção de uma nova percepção da realidade, oportunizando a ampliação da consciência e desenvolvendo, assim, o cognitivo, o afetivo, o imaginativo, ampliando o compromisso dos sujeitos com a própria vida, com a vida coletiva, com o bem comum e com a construção de uma consciência planetária.

Projetos de ensino transdisciplinares visam pensar complexo, um estilo de pensamento multidimensional e multirreferencial que problematiza a realidade e ecologiza conhecimentos científicos, saberes ancestrais e expressões estéticas inspirados pela Epistemologia da Complexidade (MORIN, 2011). A transdisciplinaridade no ensino caracteriza-se por buscar transcender a perspectiva e a organização disciplinar, sendo de tal modo coexistente e complementar (SANTOS; SOMMERMAN, 2014) à disciplinaridade. Ao buscar ampliar a compreensão sobre o fenômeno estudado, a perspectiva transdisciplinar constrói articulações entre objetividade e subjetividade, conhecimentos científicos (vinculados a diferentes áreas do conhecimento e diferentes disciplinas), saberes ancestrais, valorizando a pluralidade de ideias e de culturas, reconhecendo práticas e experiências (individuais e coletivas). O que é transdisciplinar está ao mesmo tempo entre as disciplinas, através das diferentes disciplinas, e vai mais além de qualquer disciplina (NICOLESCU, 1999). Assim produz novas conexões, posturas e novas relações com o conhecimento e com a vida.

A transdisciplinaridade pode ser institucionalizada e o item 2.2 referente a 'organização didático-pedagógica' do PDI/UFG 2018-2022 apresenta como práticas 
pedagógicas inovadoras a construção de situações de aprendizagem mais complexas, com maior grau de incerteza, citando dentre essas práticas: a) problematização que tem como base a observação da realidade social concreta, o levantamento de problemas, a teorização, a busca de alternativas para solução dos problemas detectados e o retorno à realidade. Estão presentes nesse processo o exercício da práxis e a formação da consciência como cidadãos e futuros profissionais e b) abordagem transdisciplinar: que se refere àquilo que está ao mesmo tempo entre as disciplinas, através das diferentes disciplinas e além de qualquer disciplina. Seu objetivo é a compreensão do mundo presente, para o qual um dos imperativos é a unidade do conhecimento.

A transdisciplinaridade pode compor o projeto político pedagógico, o currículo, os projetos de ensino, o plano de curso, mas também pode ser trabalhada nas brechas, nas oportunidades construídas pelos docentes em contextos concretos de luta, de contraposição e de ruptura paradigmática. Trabalhar nas brechas (MORAES, 2008; WALSH, 2020) é uma metáfora poética que pode ser capaz de deixar florescer práticas de ensino críticas, insurgências, emergentes e marginais.

Visando esta prática transdisciplinar emancipadora e inovadora, destaca-se entre os projetos de ensino da escola o Projeto Transdisciplinar O que é ser brasileiro? Um projeto coletivo que em seu processo de concepção e planejamento aproximou docentespesquisadores do CEPAE/ UFG e da FE/UFG com formação em História, Geografia, Letras e Pedagogia. No desenvolvimento do projeto contou com professores do Ensino Médio das disciplinas de Língua Portuguesa, História e Geografia do CEPAE/ UFG que, desde 2018, propõe uma investigação transdisciplinar da brasilidade por meio de textos fundadores da retórica nacional, tendo por eixo fundamental obras literárias que contribuem para esta pesquisa.

O projeto conta com a participação de alunos do Educação Básica, bolsistas PIBIDs, estagiários das três áreas além de mestrandos do PPGEEB, o Mestrado Profissional Multidisciplinar em Ensino e Educação Básica do CEPAE/ UFG.

\section{O Mestrado Profissional em Ensino na Educação Básica do CEPAE/UFG}


Uma vez que o CEPAE/ UFG já atendia da Educação Infantil ao Ensino Médio, além de oferecer cursos de pós-graduação Lato Sensu, de especialização presencial e também à distância, faltava ao centro proporcionar um mestrado profissional para docentes da Educação Básica a fim de trocar e compartilhar com esses profissionais o conhecimento e parte da experiência e estrutura do colégio. Com este intuito, o Programa de Pós-Graduação em Ensino na Educação Básica do CEPAE/UFG começou a ser desenhado em 2008, no bojo das transformações e ampliações em curso com o Programa de Apoio ao Plano de Reestruturação e Expansão das Universidades Federais (REUNI).

Corroboraram no desenvolvimento do programa de pós-graduação o fato de que, conforme anunciado no item anterior deste artigo, o Centro de Ensino e Pesquisa Aplicada à Educação tinha desde seus primórdios sido concebido para atuar não só como uma escola, mas também contribuindo com o processo de formação continuada de profissionais da educação, fundamentalmente por meio da realização dos estágios obrigatórios supervisionados. Assim, a concepção de um programa de pós-graduação com um mestrado profissional voltado ao ensino na Educação Básica foi mais um passo, um desdobramento, do sentido e da razão de ser desta unidade da Universidade Federal de Goiás.

Entre os anos de 2010 e 2011 foi criada e mantida a Comissão de Estruturação do Mestrado do CEPAE/UFG, composta por docentes desta unidade, bem como por técnicos administrativos, contando com assessoria da Pró-Reitoria de Programas de Pós-Graduação da Universidade Federal de Goiás (PRPPG/UFG). Nesse período de estruturação, a CAPES orientou que a então criada Área de Ensino (n.46 da lista Capes) era a mais apropriada para constituição de um programa de pós-graduação para o CEPAE/ UFG. Então:

Tendo como fundamento as investigações desenvolvidas em pesquisas científicas, sistematizadas e veiculadas em livros, materiais didáticos, artigos e outras publicações, bem como em eventos e outras atividades acadêmicas, a Comissão decidiu organizar um Programa de Pós-Graduação em Ensino na Educação Básica (PPGEEB), em nível de Mestrado, na modalidade Profissional, cuja proposta curricular contemplasse os diferentes campos de atuação do ensino na Educação Básica de forma multidisciplinar. Para tanto, foi idealizada uma matriz composta por três núcleos que, imbricados, pudessem oferecer (1) uma formação geral relacionada às questões da Educação e do Ensino Escolar no Brasil, (2) um aprofundamento epistemológico específico dos conteúdos disciplinares e de suas práticas em contextos formais, não formais e informais de ensino, e (3) uma imersão em temas sociais diversos, apresentados, discutidos e vivenciados em encontros científicos e ambientes educacionais que, sistematizados e apresentados em

Revista Devir Educação, Lavras, vol.2, n.4, p.34-54 jul./dez., 2020. 
forma de dissertação acadêmica, ao final de vinte e quatro meses, fundamentassem o estudo teórico de um objeto que desse sustentação à formulação de propostas de atividades práticas aplicadas à escolarização básica. (PPGEEB/UFG, p.8: 2019)

A primeira turma do PPGEEB/UFG começou seus estudos, aulas e pesquisas em 2013, com 19 discentes de variadas áreas do conhecimento. O processo seletivo contou, neste primeiro ano, com 120 candidatos. Já em aula inaugural da segunda turma do mestrado profissional, realizada no dia 06 de março de 2014, o Pró-Reitor de Pós-Graduação, Prof. Dr. José Alexandre Felizola Diniz Filho, falou sobre a relevância da pesquisa aplicada em Educação Básica e reiterou o compromisso da UFG em buscar bolsas em instituições de fomento e recursos para a divulgação e publicação dos produtos educacionais advindos das dissertações desenvolvidas no Programa. Na abertura do evento, o Prof. Dr. João Henrique Suanno (UEG/Goiânia - RIEC/Barcelona) explicou a importância da parceria firmada entre o PPGEEB e a Rede Internacional de Escolas Criativas, e anunciou que os mestrandos da 1a turma divulgariam suas pesquisas e produtos educacionais no I Seminário da Rede Internacional de Escolas Criativas, organizado pelas Universidade Federal de Goiás, Universidade Estadual de Goiás e Universidade de Barcelona, e realizado no CEPAE/ UFG, nos dias 26, 27 e 28 de março de 2014.

No final de 2016 o Programa de Pós-Graduação em Ensino na Educação Básica já havia titulado 36 mestres em Ensino na Educação Básica. O processo seletivo de 2017 obteve 37 aprovados com uma média de 10 candidatos por vaga, fato que evidenciou o reconhecimento histórico da atuação e excelência do CEPAE/ UFG na comunidade acadêmica em Goiás. Até o último processo seletivo, realizado em 2019, o Programa de Pós-Graduação em Ensino na Educação Básica consolidou-se como um dos programas da Universidade Federal de Goiás com maior procura, chegando a ter cerca de quatrocentos candidatos inscritos.

Em 2019, nosso programa seguiu sendo grande, com quadro multidisciplinar de 24 professores-orientadores de Matemática, Pedagogia, Geografia, História, Educação Física, Língua Portuguesa, Filosofia, Sociologia, quadro este ampliado a cada ano. De fato, para o primeiro processo seletivo para 2019, ocorrido entre junho e dezembro de 2018, estavam 
inscritos 385 candidatos, com a aprovação de 28 deles. No segundo processo, ocorrido entre janeiro e julho de 2019, houve 238 candidatos com a aprovação de 23 deles, totalizando a admissão de 51 novos ingressantes neste ano. Tal procura ratifica a importância deste programa, que atende fundamentalmente a docentes das escolas públicas do Estado de Goiás ${ }^{9}$, um dos programas mais concorridos na esfera dos mestrados da nossa universidade.

É digno de nota que desde o primeiro ano de existência do Mestrado do CEPAE/ UFG as relações com as pesquisas educacionais escolares não só em rede nacional, mas também internacional, promovem o diálogo e as parcerias entre ensino e pesquisa em ambientes escolares, fomentando experiências educacionais criativas e inovadoras. Com efeito, desde seu primeiro ano de funcionamento o PPGEEB/CEPAE/UFG passou a organizar seu seminário interno, promovendo um momento de encontro e de apresentação das pesquisas em curso no programa.

Nas atividades destinadas à semana inaugural de 2019 foi realizada uma roda de conversas com a participação de ex-discentes do programa, que puderam compartilhar suas experiências e suas pesquisas com os ingressantes.

Nessa oportunidade, os egressos, Professor Me. Leonarlley Barbosa e a Profa. Ma. Siely Guimarães, dialogaram com alunos e professores presentes sobre o processo de pesquisa que desenvolveram ao longo do mestrado (Cf. https://www.instagram.com/p/BvR_4CZnRWb/ ). A dissertação de Leonarlley, intitulada "Jornal Folhinha Aplicada on-line: um exercício de autoria", discute as práticas de leitura e escrita em relação à construção da autoria, por parte de alunos do Ensino Fundamental, e como as tecnologias digitais podem favorecer esse processo. Para isso, ele desenvolveu o "Folhinha Aplicada" como seu Produto Educacional, um periódico que se mantém ativo e publica textos de alunos de todo o Brasil e do exterior, como se pode apreciar em: <https://www.folhinhaaplicada.com/>, como também em: <https://www.instagram.com/folhinhaaplicada/>.

Já o trabalho da Professora Ma. Siely Guimarães apresenta uma investigação sobre a própria prática de ensino de matemática, a partir da análise de erros como estratégia didática em suas aulas. A partir dessa investigação, o produto educacional foi desenvolvido em forma de um e-book. Esse produto

\footnotetext{
${ }^{9}$ Conforme já anunciamos neste texto, o Programa de Pós Graduação em Ensino na Educação Básica não se volta com exclusividade para docentes das escolas públicas, recebe também professoras e professores de escolas privadas, bem como de educadores que atuam e processos informais e nãoformais de ensino, mas é notório que grande parte dos mestrandos e mestrandas do nosso programa advém de escolas públicas municipais e estaduais de Goiás, com ênfase numérica aos municípios de Goiânia e Aparecida de Goiás, os mais populosos de Goiás.
} 
foi escrito, a partir de uma "reflexão na e sobre a ação" com enfoque na análise de erros, contemplando os resultados da presente pesquisa por meio de narrativas reflexivas, compartilhando a experiência obtida com o lidar e

aprender com esses erros. (Disponível em: $\langle$ http://www.educapes.capes.gov.br/handle/capes/561351)>.(PPGEEB/UFG, p.16: 2019)

\section{Algumas experiências do mestrado multidisciplinar do CEPAE/ UFG}

Como já se salientou aqui, o alunado do mestrado profissional do CEPAE/ UFG é composto em sua maioria por professores da rede pública de ensino. Necessariamente, se o candidato não comprovar vínculo com alguma instituição de Educação Básica, não poderá ingressar no programa. São, portanto, professores na ativa, que muitas vezes cumprem dois turnos de aulas, além de cursar nosso mestrado. Vale dizer que muito raramente estes professores obtêm uma licença para cursar as disciplinas. São profissionais que, apesar do alto custo humano, desejam e se propõem a investir em seu aprimoramento docente, uma vez que as oportunidades de formação continuada oferecidas pelas redes públicas são escassas ou mesmo inexistentes. Percebe-se, portanto, o compromisso dos professores com a educação, apesar da falta de incentivo, dos salários baixos, da jornada extenuante, do desprestígio social desta classe de profissionais.

No mestrado profissional, apesar de o aluno ter que estar vinculado a alguma instituição de Educação Básica, estar efetivamente empregado e trabalhando, deve, além das obrigações de um mestrado acadêmico - cursar as disciplinas, realizar pesquisas, participar de eventos e redigir a dissertação - propor e cumprir uma intervenção em uma escola onde será realizada uma pesquisa de campo, ou seja, criar e aplicar um plano de ensino e, enfim, criar um produto educacional. Por ser uma intervenção em que envolve seres humanos, crianças, na grande maioria das vezes, o mestrando, ainda, deve submeter seu projeto ao comitê de ética que determina a solicitação tanto à escola campo, quanto aos alunos e pais de alunos que assinem o Termo de Consentimento Livre e Esclarecido (TCLE) e o Termo de Assentimento Livre e Esclarecida (TALE). O mestrando apresenta, ao final, três produções - a sequência didática, a dissertação e o produto educacional. 
Apesar de tanta exigência, nosso programa segue cada vez mais concorrido, como se demonstrou, por professores da capital e do interior, o que demonstra a enorme carência formativa de professores de todas as licenciaturas no estado, uma verdadeira crise cujas razões qualquer profissional da área do ensino sabe dizer: desprestígio da classe de professores, baixos salários, falta de incentivo para formação continuada, entre outros. A verdade é que as licenciaturas, em geral, são marginalizadas em relação aos demais cursos universitários. Para Benedito Antunes (2015, p.8), "uma das primeiras consequências da crise da licenciatura é a preparação insuficiente daqueles que ainda se interessam pela profissão.”

De nossa parte, tanto como professores da Educação Básica como da pós-graduação, atuamos como pontes entre estas duas extremidades da formação, uma condição que os mestrados acadêmicos não oferecem, o que é uma limitação importante, uma vez que a grande maioria dos mestres formados em mestrados - acadêmicos ou não - atuarão na Educação Básica. Neste sentido, algumas experiências, entre muitas, serão relatadas aqui.

Em todas as seleções de candidatos ao Programa de Pós-graduação em Ensino na Educação Básica, algumas áreas destacam-se como mais concorridas, entre elas a de Língua Portuguesa e de Pedagogia. A fim de ingressarem no programa, além das três etapas de seleção - prova, projeto e entrevista - ainda há uma seleção do orientador. Sendo 7 professoras de Português do CEPAE/ UFG, todo ano há mais candidatos do que professores para orientarem suas pesquisas. Fazemos o possível para atender ao maior número de alunos, mas inevitavelmente alguns não entram ou entram como alunos especiais.

No departamento de Língua Portuguesa do CEPAE/ UFG, 3 professoras são pesquisadoras do projeto de pesquisa Formação do leitor literário na Educação Básica e levam este projeto também para o mestrado. Tal projeto é caro ao departamento, uma vez que entendemos que a leitura em geral e a leitura literária em particular é ferramenta eficiente de desenvolvimento intelectual, social, emancipação, incremento de "capital cultural" (BOURDIEU, 2012) de alunos. Para Candido (2004), a literatura é um bem incompreensível como o alimento e a moradia, direito de todo cidadão e fator humanizador, uma vez que é

o processo que confirma no homem aqueles traços que reputamos essenciais, como o exercício da reflexão, a aquisição do saber, a boa disposição para com o próximo, o afinamento das emoções, a capacidade de penetrar nos problemas da vida, o senso da beleza, a percepção da complexidade do mundo e dos seres, o cultivo do humor. (p.180)

Revista Devir Educação, Lavras, vol.2, n.4, p.34-54 jul./dez., 2020. 
Outrossim, para Colomer, a literatura liberta e atua como forma de emancipação. "Não se ensina literatura para que todos os cidadãos sejam escritores, mas para que nenhum seja escravo.”. (COLOMER, 2007, p.35). Para a autora:

O objetivo da educação literária é, em primeiro lugar, o de contribuir para a formação da pessoa, uma formação que aparece ligada indissoluvelmente à construção da sociabilidade e realizada através da confrontação com textos que explicitam a forma em que as gerações anteriores e as contemporâneas abordaram a avaliação da atividade humana através da linguagem. (2007, p. 21).

\section{Narrativa infanto-juvenil e formação de jovens leitores: por novos horizontes no}

ensino de literatura, da mestranda Débora Almeida Rodrigues de Almeida e orientação da professora Dra. Vivianne Fleury de Faria, é uma das pesquisas do nosso mestrado que levam adiante o projeto de formação do leitor literário na Educação Básica. Em fase conclusão, já qualificada, essa proposta surgiu das indagações da pesquisadora como professora da Educação Básica dos anos iniciais do Ensino Fundamental. À aluna interessava a pesquisa sobre obras literárias para crianças que abordassem a diversidade e a inclusão de forma crítica. Sua hipótese de pesquisa é: seria possível abordar com alunos da Educação Infantil obras literárias que não coadunem com o padrão racial e cultural das narrativas tradicionais, profundamente eurocêntricas? Como estas obras seriam recebidas pelos alunos? A fim de confirmar ou não sua hipótese de trabalho, a mestranda traçou seu objetivo geral - formação do leitor literário na Educação Básica.

O projeto de intervenção foi aplicado em uma escola-campo na periferia de Goiânia por meio de uma pesquisa-ação. Neste tipo de pesquisa o pesquisador é também interventor e promove mudanças significativas no universo em que atua. Para Singer (2011, p. 24):

A pesquisa-ação baseia-se na construção coletiva do conhecimento e na relação contínua entre experiência e reflexão. A visão de mundo que embasa a pesquisa-ação é a de que todos os indivíduos são autônomos e o processo educativo visa apenas fazer com que eles reconheçam e realizem sua autonomia, sua potência de conhecer. Neste sentido, remete a uma característica do pensamento humano: a reflexão sobre a experiência a fim de aprimorá-la [...]. 
De fato, após pesquisa na literatura infantil de obras que abordassem a temática racial e que representassem acultura africana e afro-brasileira, a pesquisadora confirmou que muitas delas ao invés de combater e desmascarar o racismo existente na sociedade brasileira, acabam por ratificá-lo e reproduzi-lo, mesmo que essa não seja intenção de seus autores. Não é o caso da obra escolhida para esta intervenção - Obax - texto e ilustração de André Neves. O trabalho exitoso com esta obra de extremo apuro estético proporcionou aos alunos, todos eles de extratos marginalizados da sociedade, a reflexão sobre sua condição social na medida em que promoveram a empatia pelo outro - a menina negra Obax, que vive aventuras fantásticas nas savanas africanas. A partir desta pesquisa-ação foi confirmada a hipótese levantada no início do trabalho e atingido o objetivo geral determinado.

Não menos importante para a pesquisadora era o viés inovador da proposta. Os sujeitos desta pesquisa eram crianças de uma mesma turma multietária de 25 crianças, de 6 a 8 anos, sendo que na época apenas 12 delas eram alfabetizadas. Isso propiciou um trabalho inovador na medida em que havia entre os alunos uma relação de tutoria dos mais velhos e experientes com a leitura em relação aos mais jovens e ainda não alfabetizados. A leitura de Obax se deu, portanto, respeitando os diferentes ritmos e modos de assimilação dos alunos conforme suas potencialidades e de forma reflexiva.

Ao final da experiência houve um completo envolvimento da turma com esta obra de arte, bem como foi atingido o objetivo maior de levar estas crianças a apropriarem-se do objeto literário de forma afetuosa e crítica, o que favorecerá próximas leituras e, assim, a formação de seu gosto literário. Prova deste sucesso são os desenhos, depoimentos e narrativas produzidos por estas crianças e que constituirão um vídeo ainda em construção, o produto educacional desta pesquisa.

Outra experiência de pesquisa bem sucedida, essa já concluída, do nosso programa que destaca-se foi realizada pelo professor e pesquisador Jean Marcos da Silva. Sua pesquisa, intitulada $O$ ensino da Geografia em classe hospitalar/domiciliar: desafios, práticas e possibilidades foi realizada no Núcleo de Atendimento Educacional Hospitalar (NAEH) de Goiás, onde o pesquisador atua na condição de docente efetivo. A pesquisa foi realizada entre os anos de 2017 e 2019, e contou com a orientação do prof. Dr. Glauco Roberto Gonçalves.

Esta pesquisa é mais uma que evidencia objetivamente uma característica marcante do nosso programa de pós-graduação, que é a possibilidade de docentes operarem como pesquisadores e pesquisadoras em seu campo profissional, efetivando pesquisas em ambientes 
de trabalho que já conhecem e onde trabalham às vezes por anos, ou mesmo por décadas. Tais pesquisas trazem à tona conhecimentos acumulados no campo da docência de forma rica e única, promovem possibilidades metodológicas intrigantes, pois lançam o desafio de conjugar a condição da docência e da pesquisa concomitantemente. No mais, pesquisar a realidade educacional em que se atua oferece a possibilidade de pensar suas próprias práticas pedagógicas e ampliar seus horizontes de ação, bem como promover conhecimentos que não só contribuem para o entendimento de uma dada realidade objetiva como podem contribuir efetivamente em termos qualitativos e práticos diante de tal realidade.

A pesquisa sobre classes hospitalares feita pelo professor-pesquisador Jean Marcos da Silva é um caso que ratifica o que afirmamos anteriormente. Jean se moveu como pesquisador diante de uma realidade na qual trabalha como professor há décadas, uma conjuntura que ele conhece profundamente e sobre a qual tem notória experiência. Uma realidade bastante específica e com características bastante peculiares, pois o ensino em classes hospitalares oferece desafios únicos.

A dissertação de Jean traça um histórico das classes hospitalares no mundo e no Brasil, enfatizando os processos jurídicos e legislativos que as constituem, para depois apontar o surgimento, a história e as características de funcionamento do Núcleo de Atendimento Educacional Hospitalar (NAEH) de Goiás. O pesquisador realizou levantamentos numéricos sobre os atendimentos feitos pelo núcleo ao longo de sua existência. Entrevistou docentes que atuam no NAEH, bem como entrevistou e conversou com responsáveis por estudantes atendidos. A somatória destes dados foi agrupada em gráficos e tabelas analisados qualitativamente.

O terceiro e último capítulo da dissertação de Jean Marcos da Silva merece destaque, nele o autor escreve sobre suas próprias experiências ao longo dos muitos anos como professor do Núcleo Educacional Hospitalar. Ele reativou memórias, narrou episódios marcantes, retomou diálogos expressivos com estudantes, colegas docentes e com pais e mães destes alunos e alunas. Sua escrita fluída foi preenchida por fatos, dados e conhecimentos que só o tempo das longas vivências poderiam trazer a um pesquisador e seu texto.

O produto educacional advindo desta pesquisa está diretamente associado às práticas pedagógicas, suas especificidades e possibilidades, no campo das classes hospitalares. Sua longa experiência docente favoreceu a construção de um produto com ênfase no uso de músicas para erigir saberes e conhecimentos no campo das ciências humanas, mais 
notadamente no ensino de Geografia, mas com esse viés transdisciplinar que a música sugere. A própria condição e possibilidades de atuação docente em classes hospitalares é convidativa para o exercício de práticas transdisciplinares.

Tal produção foi ampliada e revisada em conjunto com seu orientador e tornou-se um e-book, de circulação gratuita e facilmente disponível na internet, intitulado: "Ensino por meio da música em ciências humanas: uma prática possível”. Neste livro digital estão selecionadas e agrupadas algumas dezenas de canções brasileiras, de variados ritmos e épocas, com temáticas que vão da urbanização, questões ambientais, globalização e violência, dentre outras.

\section{Considerações finais}

A interface das pesquisas com as práticas docentes coloca em movimento uma profunda e profícua relação entre ensino e pesquisa, permitindo que docentes tragam conhecimentos adquiridos e vividos na escola para o conhecimento acadêmico, eis uma característica marcante do nosso programa.

Os resultados desta pesquisa documental sobre o Programa de Pós Graduação em Educação em Ensino Básico do Centro de Ensino e Pesquisa Aplicada à Educação da Universidade Federal de Goiás (PPGEEB/CEPAE/UFG) apresentou articulações entre ensino, pesquisa, extensão e mestrado profissional, tendo destacado, a título de exemplificação, que a partir de 2012 o CEPAE/ UFG passou a integrar a Rede Internacional de Escolas Criativas (RIEC), o que oportunizou a realização do I Seminário da Rede Internacional de Escolas Criativas (ANAIS, 2014) e do VII Fórum Internacional de Inovação e Criatividade e II Seminário da Rede Internacional de Escolas Criativas (ANAIS, 2015). Tais eventos geraram a publicação de dois livros (SUANNO, SILVA E FARIA, 2014; SUANNO, SILVA E FARIA, 2016) com capítulos produzidos pelos docentes do CEPAE/ UFG e do PPGEEB no intuito de registrar e compartilhar práticas e projetos de ensino desenvolvidos na Educação Básica e na Pós-graduação na referida instituição. Em 2018, o projeto de ensino intitulado Projeto Transdisciplinar $O$ que é ser brasileiro? foi um marco no trabalho coletivo de três docentes do ensino médio do CEPAE/ UFG e este contou com a participação de estudantes do ensino 
médio, bolsistas PIBIDs, estagiários de cursos de licenciatura, mestrandos do PPGEEB/CEPAE/UFG e uma professora da Faculdade de Educação UFG. As pesquisas e os produtos educacionais do PPGEEB são construídos em um contexto escolar ímpar, pois o CEPAE/ UFG conta com educação infantil, ensino fundamental e ensino médio, além do Mestrado Profissional em Ensino na Educação Básica, contando com diversas ações de extensão, pesquisa e publicação.

A universidade cumpre seu papel de modo ativo ao favorecer não só a ampliação e aprofundamento da formação de professores e professoras que atuam nas redes estaduais, municipais, federal e também privadas, em Goiás, mas também efetiva um papel não menos importante de promover possibilidades de entendimento ampliado das condições de ensino em espaços formais, informais e não formais na Educação Básica, favorecendo a ampliação das possibilidades e da qualidade de ensino na Educação Básica, seja ela privada ou pública, seja em escolas de grandes centros urbanos, como Goiânia, Anápolis ou Aparecida de Goiás, ou de municípios menores do interior do Estado, e mesmo de escolas rurais, de onde vem parte dos nossos mestrandos e mestrandas. Esta é a vocação do PPGEEB/CEPAE /UFG e nosso maior desafio, ano a ano superado.

\section{Referências}

ANTUNES, Benedito. O ensino da literatura hoje. FronteiraZ - Revista do Programa de Estudos Pós-Graduados em Literatura e Crítica Literária. nº 14, jullho de 2015. Disponível em: https://revistas.pucsp.br/index.php/fronteiraz/article/view/22456/17058. Acesso em 10/05/2020.

BOURDIEU, Pierre. Escritos da educação. Rio de Janeiro: Vozes, 2012.

CANDIDO, Antonio. Vários escritos. 4. ed. São Paulo: Duas Cidades, 2004.

COLOMER, Teresa. Andar entre livros. A leitura literária na escola. Tradução: Laura Sandroni. São Paulo: Global, 2007. Edição PNBE do professor, 2013.

FERREIRA, Maria J. de M.; GONZAGA, Deusimar. Colégio de Aplicação: 40 anos de Educação em Goiânia. Goiânia, Cegraf-UFG, 2008.

FREIRE, Paulo. Pedagogia do oprimido. Rio de Janeiro: Editora Paz e Terra, 2005.

GONÇALVES, Glauco Roberto. Pedagogia da ocupação (e ocupação da pedagogia): as escolas ocupadas e suas práticas de educação democrática no Ensino Básico. In: MESQUITA, 
Deise, N. C. (org.) Escola de educação básica para todos. Goiânia: Editora Espaço Acadêmico, 2017, v. 1, p.52-68.

LUCARELLI, Elisa. Teoría y prática em la universidad: La innovación em las aulas. Buenos Aires: Miño y Dávila Editora, 2009.

MESQUITA, Deise Nanci de Castro (org). Centro de Ensino e Pesquisa Aplicada à Educação da Universidade Federal de Goiás: 50 anos de história. Goiânia, Gráfica da UFG, 2018.

MORAES, Maria Cândida. Ecologia dos saberes: complexidade, transdisciplinaridade e educação - novos fundamentos para iluminar novas práticas educacionais. São Paulo: Antakarana/WHH - Willis Harman House, 2008.

6

MORIN, Edgar. La Vía. Para el futuro de la humanidade. Tradução Núria Petit Fontseré. Barcelona: Paidós, 2011.

NICOLESCU, Basarab. O Manifesto da transdisciplinaridade. São Paulo: Triom, 1999. UFG. PDI/UFG 2018-2022. Disponível em: https://www.ufg.br/up/1/o/PDI_UFG__Plano_de_desenvolvimento_institucional_2018-2022.pdf. Acesso em 20/07/2020.

OLIVEIRA, Isadora Malveira.; PEIXOTO, Stefany Monteiro. Grêmio Damiana da Cunha: uma análise teórica e empírica das transformações no CEPAE. In: MESQUITA, Deise N. de C (org). Centro de Ensino e Pesquisa Aplicada à Educação da Universidade Federal de Goiás: 50 anos de história. Goiânia, Gráfica da UFG, 2018, v.1, p.45-63.

PROGRAMA DE PÓS GRADUAÇÃO EM ENSINO NA EDUCAÇÃO BÁSICA. Proposta do PPGEEB/CEPAE/UFG: Relatório CAPES 2019.

SANTOS, Akiko \& SOMMERMAN, Américo. Ensino disciplinar e transdisciplinar: uma coexistência necessária. Rio de Janeiro: WAK, 2014.

SILVA, Alcir, Horácio. CEPAE/UFG 50 anos de História. In: Centro de Ensino e Pesquisa Aplicada à Educação da Universidade Federal de Goiás: 50 anos de história. Deise N. de C. Mesquita (org), Goiânia, Gráfica da UFG, 2018, v.1, p.12-20.

SILVA, Jean, M. O Ensino da Geografia em classe hospitalar/domiciliar: desafios, práticas e possibilidades. 2019, 197 p. Dissertação (Mestrado profissional em Ensino) Universidade Federal de Goiás, Goiânia, 2019.

SILVA, Jean, M.; GONÇALVES, Glauco Roberto. Ensino por meio da música em ciências humanas: uma prática possível sugestões de músicas para serem utilizadas como recursos didáticos em classes regulares e hospitalares em Goiás. 1 ed. Goiânia: Editora Espaço Acadêmico, 2019.

SINGER, Helena. Definição e característica da pesquisa ação-comunitária. In: SINGER, Helena (org). Cidade Escola Aprendiz - Coleção Tecnologias do Bairro Escola: Volume 1 - 
Pesquisa-ação Comunitária. São Paulo: Associação Cidade Escola Aprendiz/Fundação Itaú Social, 2011. p. 16-33.

SUANNO, Marilza Vanessa Rosa et al (Org.). Anais do I Seminário da Rede Internacional de $\begin{array}{lllll}\text { Escolas Criativas. } & \text { Goiânia: } & \text { Editora } & \end{array}$ https://files.cercomp.ufg.br/weby/up/80/o/Escolas_Criativas_Final.pdf. Acesso em 13/02/2020.

SUANNO, Marilza Vanessa Rosa et al (Org.). Anais do VII Fórum Internacional de Inovação e Criatividade e II Seminário da Rede Internacional de Escolas Criativas. 03, 04 e 05 de setembro de 2015. Goiânia: Editora UFG, 2016. 1996 p. Disponível em: https://www.cepae.ufg.br/p/11329-riec-2015. Acesso em 13/02/2020.

SUANNO, Marilza Vanessa Rosa. Didática e trabalho docente sob a ótica do pensamento complexo e da transdisciplinaridade. Brasília: 2015. 493 f. Tese (Doutorado Educação) Faculdade de Educação, Universidade Católica de Brasília.

SUANNO, Marilza Vanessa Rosa; SILVA, Rusvênia Luiza Batista Rodrigues da; FARIA, Vivianne Fleury de (Orgs). Veredas escolares: partilhando experiências criativas de ensino e aprendizagem do CEPAE/UFG. Goiânia: Gráfica e Editora América, 2014. 360 p. Disponível em: https://files.cercomp.ufg.br/weby/up/80/o/Veredas_escolares_site.pdf. Acesso em $\underline{13 / 02 / 2020 .}$.

SUANNO, Marilza Vanessa Rosa; SILVA, Rusvênia Luiza Batista Rodrigues da; FARIA, Vivianne Fleury de (Orgs). Veredas Escolares II: Partilhando experiências criativas de ensino e aprendizagem do CEPAE/UFG. Goiânia: Editora Espaço Acadêmico, 2016. Disponível em: https://files.cercomp.ufg.br/weby/up/80/o/veredas_escolaresII_miolo_para_internet_(1).pdf. Acesso em 13/02/2020.

WALSH, Catherine. Pedagogías Decoloniales: Insurgencias desde las Grietas. Disponível em: https://www.youtube.com/watch?v=SuMPMn4sOuc\&t=1109s. Acesso em 20/06/2020.

Recebido em: 07/07/2020

Aprovado em: 25/08/2020

Revista Devir Educação, Lavras, vol.2, n.4, p.34-54 jul./dez., 2020. 